\title{
Long-term prognosis of nerve palsy after total hip arthroplasty: results of two-year-follow-ups and long-term results after a mean time of 8 years
}

\author{
B. Zappe $\cdot$ P. M. Glauser $\cdot$ M. Majewski $\cdot$ H. R. Stöckli $\cdot$ \\ P. E. Ochsner
}

Received: 27 December 2013 / Published online: 6 July 2014

(C) Springer-Verlag Berlin Heidelberg 2014

\begin{abstract}
Introduction Nerve damage is a rare but serious complication after THA. There exist only little data about the outcome of these patients particularly regarding the longterm results later than 2 years postoperatively. Aim of this study is to answer the following questions: Is the recovery to be expected for light nerve lesions different from the severe ones? Is there a possibility of nerve recovery more than 2 years after THA? Is the potential of nerve recovery depending on the affected nerve?

Materials and methods This study investigates 2,255 primary THA as well as revision surgeries performed from 1988 to 2003 relating to iatrogenic nerve lesion. We classified the nerve lesion according to the core muscle strength in severe (M0-M2) and light (M3-M4) nerve damage and differentiated between femoral, sciatic and superior gluteal nerve, according to the electromyography.

Results We found 34 cases of iatrogenic nerve damage representing an incidence of $1.5 \% .17$ of $34(50 \%)$
\end{abstract}

B. Zappe $(\varangle) \cdot$ P. M. Glauser

Department of Traumatology, University Hospital, 4031 Basel,

Switzerland

e-mail: bjoern.zappe@usb.ch

M. Majewski

Department of Orthopedic Surgery, University Hospital, Basel,

Switzerland

H. R. Stöckli

Kantonsspital Liestal, Liestal, Switzerland

P. E. Ochsner

Department for Orthopaedic Surgery, Kantonsspital Liestal,

Liestal, Switzerland patients showed a complete recovery after 2 years. Out of the remaining 17 patients, six out of seven patients with a final examination after a median time of 93 months achieved further improvement. The different nerves showed no significant different potential of recovery.

Conclusions In contrast to the literature, an improvement beyond the limit of 2 years is probable and independent of the nerve affected.

Keywords Nerve lesion - Total hip arthroplasty · Longterm prognosis · Potential for recovery

\section{Introduction}

Perioperative iatrogenic nerve damage after total hip arthroplasty (THA) is a fatal complication. Even though several risk factors like dysplasia, revision surgery, posttraumatic osteoarthritis, limb lengthening and female gender are well known the incidence persisted on a fairly constant level $(0.17-3.2 \%)$ during the last 30 years [2, $5-7,9,10]$. However, there are just a few studies referencing the long-term prognosis of nerve damage considering the influence of the severity of damage as well as the type of the affected nerve $[4,14]$. On the other hand a prognosis about the development and possibility of rehabilitation would be immensely helpful for patients as well as for surgeons.

Aim of the study was to observe affected patients and to answer the following questions: which prognoses can be made concerning the potential for recovering of the nerve lesion? Is the potential of recovery related to the severity of the nerve damage observed? How long can we expect further recovery? Are there differences among different nerves? 


\section{Patients and method}

Patients

This work is based on a retrospective analysis of a prospective-maintained database to detect neurological deficits immediately, postoperatively, after THA on all patients in our clinic from January 1988 until December 2003. Inclusion criteria were planned THA and normal preoperative neurological exam on the day before surgery. Preoperative electromyography (EMG) was not performed. We included 2,162 patients with overall 2,255 primary implanted THAs or revision surgeries. All THA patients got clinical and radiological examinations 6 weeks, 4 months, 1 and 2 years after surgery. The results of all examinations were documented in the International Documentation and Evaluation System (IDES) [13].

\section{Surgery and implants}

The majority of patients have been operated in a supine position using the transgluteal approach according to Bauer [1]. Only 51 operations in 49 patients were performed in lateral position. In rare exceptions, in which the planned elongation of one leg was more than $4 \mathrm{~cm}$, the sciatic nerve was explored using a dorsal approach with a special emphasis on a careful approach and placing of surgical instruments as well as surgical hooks $[11,15]$. In most of the cases, a "Muller Straight Stem" and an uncemented cup were used. All operations were conducted by or under the supervision of a senior orthopedic surgeon (consultant).

Identification and classification of nerve damage

Standardized examinations of the function of the femoral, sciatic and superior gluteal nerve were performed on all patients pre- and postoperatively. The function of the femoral nerve was tested by examining the active knee extension and the sciatic nerve by testing the function of the feet and the extensor muscle of the toes. The superior gluteal nerve could only be approximately estimated by active abduction in the hip against resistance caused by the examiner [11]. We classified the deficit in muscular strength of the core muscle in M0-M5 according to Daniels et al. [3] (Table 1). Hereby we defined M0-M2 as severe, M3-M4 as light nerve damage. All patients who were detected with deficit in muscular strength were examined by EMG, to objectify the nerve damage. So, we could differentiate nerve damages according to the intervention from positional damage.

Empirical final examination

Patients not showing full recovery after 2 years were contacted for a final examination. Gait pattern, muscle strength
Table 1 Classification of muscle function adapted from Daniels et al. [3]

Grades of muscle function

M0: no contraction or muscle movement

M1: trace of contraction, but no movement at the joint

M2: movement at the joint with gravity eliminated

M3: movement against gravity, but not against added resistance

M4: movement against external resistance, but less than normal

M5: normal strength

of the core muscle were tested including a neurological status of the lower extremities and an EMG. During the whole study period the same neurologist did all the testing.

Statistics

We used SPSS ${ }^{\circledR}$ version 17.0 for Windows (SPSS Inc, Chicago, IL, USA) for the statistical analyses. Categorical data are presented as absolute values and relative frequencies and continuous data as median and interquartile range (IQR). Groups have been tested for difference by Fisher's exact test or Mann-Whitney $U$ test, as appropriate.

\section{Results}

Incidence and development of nerve lesion

Overall, we documented 35 patients with postoperative nerve lesions. In one patient the electromyography showed a nerve lesion in a lower level (peroneal nerve) interpreted as a positional damage. This case was excluded from the analyses. Therefore, 34 out of 2,255 (1.5\%) patients with a mean age of 65 years (SD 10.6) which suffered from iatrogenic nerve damage after THA were included in our study. For primary surgery the incidence was $1.5 \%$ (28 out of 1,820 ), for revision surgery it was $1.4 \%$ (6 out of 435) (Table 2). According to gender the incidence for nerve lesion after THA was $2.5 \%$ in female and $0.6 \%$ in male patients ( 27 out of 1,071 vs. 7 out of 1,184). Chi-square test shows a high statistical significance for female gender as a risk factor for nerve lesion $(p<0.01)$. All these 34 patients with postoperative nerve lesion have been operated in a supine position using the transgluteal approach according to Bauer [1].

20 patients $(59 \%)$ suffered from damage of the femoral nerve, 9 patients $(26 \%)$ had a sciatic nerve lesion and 5 patients $(15 \%)$ showed damage in the superior gluteal nerve (Table 2). 23 patients (68\%) presented a severe damage, whereas $11(32 \%)$ showed a lighter nerve lesion (Table 3 ).

In all 34 patients the postoperatively performed EMG did show a neurapraxia. Neurotmesis with the need for a 
Table 2 Incidence of iatrogenic peripheral nerve injury, separated to different nerves

\begin{tabular}{lcl}
\hline Nerve & $\begin{array}{l}\text { Primary THA } \\
(n=1,820)\end{array}$ & $\begin{array}{l}\text { Revision surgery } \\
(n=435)\end{array}$ \\
\hline Femoral nerve & $18(1.0 \%)$ & $2(0.5 \%)$ \\
Sciatic nerve & $5(0.3 \%)$ & $4(0.9 \%)$ \\
Superior gluteal nerve & $5(0.3 \%)$ & 0 \\
Subtotal & $28(1.5 \%)$ & $6(1.4 \%)$ \\
Total & $34(1.5 \%)$ & \\
\hline
\end{tabular}

Table 3 Degree of damage and no. of recoveries

\begin{tabular}{lll}
\hline Nerve damage & $\begin{array}{l}\text { Light (M3-5) } \\
\text { No./no. of recovery }\end{array}$ & $\begin{array}{l}\text { Severe (M0-2) } \\
\text { No./no. of recovery }\end{array}$ \\
\hline Femoral nerve & $3 / 3$ & $17 / 9$ \\
Sciatic nerve & $5 / 5$ & $4 / 1$ \\
Superior gluteal nerve & $3 / 2$ & $2 / 0$ \\
& $11 / 10$ & $23 / 10$ \\
\hline
\end{tabular}

revision including nerve reconstruction was not found. Evacuation of postoperative haematoma is not part of our clinical standard treatment. Therefore, all patients were treated conservatively.

\section{Chronological development of improvement (Table 4)}

At the time of the 2-year-examination $17(50 \%)$ of 34 patients showed complete remission. For these patients the median duration up to complete remission was 19 months (IQR 8-24). Patients suffering from severe nerve damage needed a median time to recovery of 21 months (IQR 1524), whereas patients suffering from a light nerve damage recovered in a mean time of 13 (IQR 3-23) months.

At the final empirical examination of the seven patients controlled, additional three patients reached complete recovery; three presented slight improvement whereas only one remained unchanged. Overall, 20 out of 34 (59\%) patients had achieved complete recovery. The median duration of recovery for all patients was 21 months (IQR 1325 ). While patients with severe nerve damage had required 23 months (IQR 18-37), the patients with lighter nerve damage had needed 16 months (IQR 3-24) (Table 4).

Femoral nerve $(n=20)$

12 patients $(60 \%)$ developed complete recovery within a median of 21 months (IQR 14-25). All 3 patients with light damage did show complete remission. Of the 17 severe cases 9 took a median of 24 months (IQR 17-25) until complete remission. Of the remaining 8 cases with no complete recovery after 2 years only 2 patients were available for long-term follow-up. One achieved full recovery (No. 16) and the other improved slightly (No. 17).

Sciatic nerve $(n=9)$

All of the 5 light cases showed complete remission after a median of 13 months (IQR 3-63). One of these patients showed full recovery after 7 years (No. 25). One out of 4 severe lesions healed completely after 5 years. One did stay without any recovery at all. The remaining two were partially restored at 2 years, but died before the final control.

Superior gluteal nerve $(n=5)$

Following a light lesion only 2 out of 3 patients achieved complete remission after 2 years. The remaining case showed further improvement but only restored to M 4-5. Two severe cases presented partial recovery after 2 years. In the long-term follow-up one improved to M4, the other was lost to follow-up.

With Fig. 1 we could illustrate the chronological development of the nerve recovery dependent on each nerve. It shows once more that most of the recoveries appear within the first 25 months. But mainly the sciatic nerve and the femoral nerve too show later recoveries.

Potential for recovery

In 10 out of 11 patients with light nerve lesions complete recovery was achieved $(91 \%)$. Patients with severe nerve damage ended in complete remission in 10 out of 23 cases (43\%). In 12 cases at least partial remission was observed. Only one patient did not show any improvement at all.

For the long-term follow-up, all patients with no complete recovery after 2 years $(n=17)$ were contacted for a final exam. At that time 6 patients were dead, 3 patients were lost to follow-up and one in poor general conditions that did not allow an examination. 7 patients were controlled at a median time interval between surgery and final examination of 93 months (interquartile range (IQR) (80156) (Table 4). Six out of these 7 patients presented further improvement at the final examination. Three patients achieved full recovery to M5.

\section{Discussion}

Graduation in severe and light lesions

We believe that classifying iatrogenic nerve damage between (M0-2) as severe and (M3-4) as light is reasonable. Our graduation is more practical than the one of Farrell in "complete and incomplete lesions". The attribution 
Table 4 Temporal and qualitative development of nerve damage of all patients

\begin{tabular}{|c|c|c|c|c|c|c|c|c|c|}
\hline No & Age (years) & Sex & Side & $\begin{array}{l}\text { Degree of } \\
\text { damage }\end{array}$ & Nerve & $\begin{array}{l}\text { Muscle strength } \\
\text { postop Grade M0-5 }\end{array}$ & $\begin{array}{l}\text { Muscle strength } \\
\text { 2-year-check up } \\
\text { Grade M0-5 }\end{array}$ & $\begin{array}{l}\text { Muscle strength final } \\
\text { exam. Grade M0-5 }\end{array}$ & $\begin{array}{l}\text { Duration } \\
\text { to recovery } \\
\text { (months) }\end{array}$ \\
\hline 1 & 56 & M & Left & Light & fem & 4 & 5 & - & 3 \\
\hline 2 & 74 & M & Left & Light & fem & 3 & 5 & - & 24 \\
\hline 3 & 65 & $\mathrm{~F}$ & Right & Light & fem & 3 & 5 & - & 6 \\
\hline 4 & 50 & $\mathrm{~F}$ & Left & Severe & fem & 2 & 5 & - & 24 \\
\hline 5 & 73 & $\mathrm{~F}$ & Right & Severe & fem & 1 & 5 & - & 24 \\
\hline 6 & 70 & M & Right & Severe & fem & 1 & 5 & - & 24 \\
\hline 7 & 68 & $\mathrm{~F}$ & Left & Severe & fem & 1 & 4 & Not available & - \\
\hline 8 & 73 & $\mathrm{~F}$ & Left & Severe & fem & 1 & 3 & Dead & - \\
\hline 9 & 79 & $\mathrm{~F}$ & Right & Severe & fem & 1 & 3 & Not available & - \\
\hline 10 & 65 & $\mathrm{~F}$ & Left & Severe & fem & 0 & 5 & - & 24 \\
\hline 11 & 58 & $\mathrm{~F}$ & Left & Severe & fem & 0 & 5 & - & 24 \\
\hline 12 & 47 & $\mathrm{~F}$ & Left & Severe & fem & 0 & 5 & - & 24 \\
\hline 13 & 83 & $\mathrm{~F}$ & Left & Severe & fem & 0 & 5 & - & 24 \\
\hline 14 & 72 & M & Right & Severe & fem & 0 & 5 & - & 24 \\
\hline 15 & 69 & $\mathrm{~F}$ & Right & Severe & fem & 0 & 4 & Dead & - \\
\hline 16 & 67 & M & Left & Severe & fem & 0 & 4 & 5 & 156 \\
\hline 17 & 50 & $\mathrm{~F}$ & Left & Severe & fem & 0 & 4 & $4-5$ & - \\
\hline 18 & 71 & $\mathrm{~F}$ & Right & Severe & fem & 0 & 4 & Dead & - \\
\hline 19 & 76 & $\mathrm{~F}$ & Left & Severe & fem & 0 & 3 & Not available & - \\
\hline 20 & 72 & $\mathrm{~F}$ & Left & Severe & fem & 0 & 3 & Dead & - \\
\hline 21 & 44 & $\mathrm{~F}$ & Left & Light & sciatic & 3 & 5 & - & 12 \\
\hline 22 & 76 & $\mathrm{~F}$ & Left & Light & sciatic & 3 & 5 & - & 12 \\
\hline 23 & 58 & $\mathrm{~F}$ & Right & Light & sciatic & 3 & 5 & - & 3 \\
\hline 24 & 72 & $\mathrm{~F}$ & Right & Light & sciatic & 3 & 5 & - & 24 \\
\hline 25 & 40 & $\mathrm{~F}$ & Left & Light & sciatic & 3 & 3 & 5 & 89 \\
\hline 26 & 65 & $\mathrm{~F}$ & Left & Severe & sciatic & 0 & 4 & 5 & 60 \\
\hline 27 & 62 & $\mathrm{~F}$ & Right & Severe & sciatic & 0 & 3 & Dead & - \\
\hline 28 & 81 & $\mathrm{~F}$ & Right & Severe & sciatic & 0 & 2 & Dead & - \\
\hline 29 & 67 & M & Right & Severe & sciatic & 0 & 0 & 0 & - \\
\hline 30 & 61 & $\mathrm{~F}$ & Left & Light & sup glut & 3 & 5 & - & 24 \\
\hline 31 & 72 & $\mathrm{~F}$ & Right & Light & sup glut & 3 & 5 & - & 24 \\
\hline 32 & 61 & M & Left & Light & sup glut & 3 & 4 & $4-5$ & - \\
\hline 33 & 68 & $\mathrm{~F}$ & Right & Severe & sup glut & 1 & 3 & Demented & - \\
\hline 34 & 74 & $\mathrm{~F}$ & Left & Severe & sup glut & 0 & 3 & 4 & - \\
\hline
\end{tabular}

of M2 lesions is uncertain. We only had one such lesion amongst our cases.

Prognosis of light and severe lesions

The most positive finding is that light nerve lesions have a chance of $91 \%$ for full recovery within a median of 13 months. In contrast only $43 \%$ of severe lesions fully recover within a median of 21 months (Table 3 ). Only one of 16 M0-lesions did not show any improvement. This is in contrast to Pekkarinen et al. [14], which quoted, that it would be impossible to predict the prognosis of a nerve injury at an early stage. We also cannot confirm the saying of Farrell et al. [5] that "the majority of patients with nerve palsy—whether complete or incomplete-never fully recovered to preoperative strength." Simmons showed that in case of retractor-related injury of the femoral nerve all his patients showed full recovery [17]. But he did not differentiate between mild and severe nerve injuries. Furthermore the significant higher incident in female gender indicates that it is not mainly a question of a retractor-related problem. 


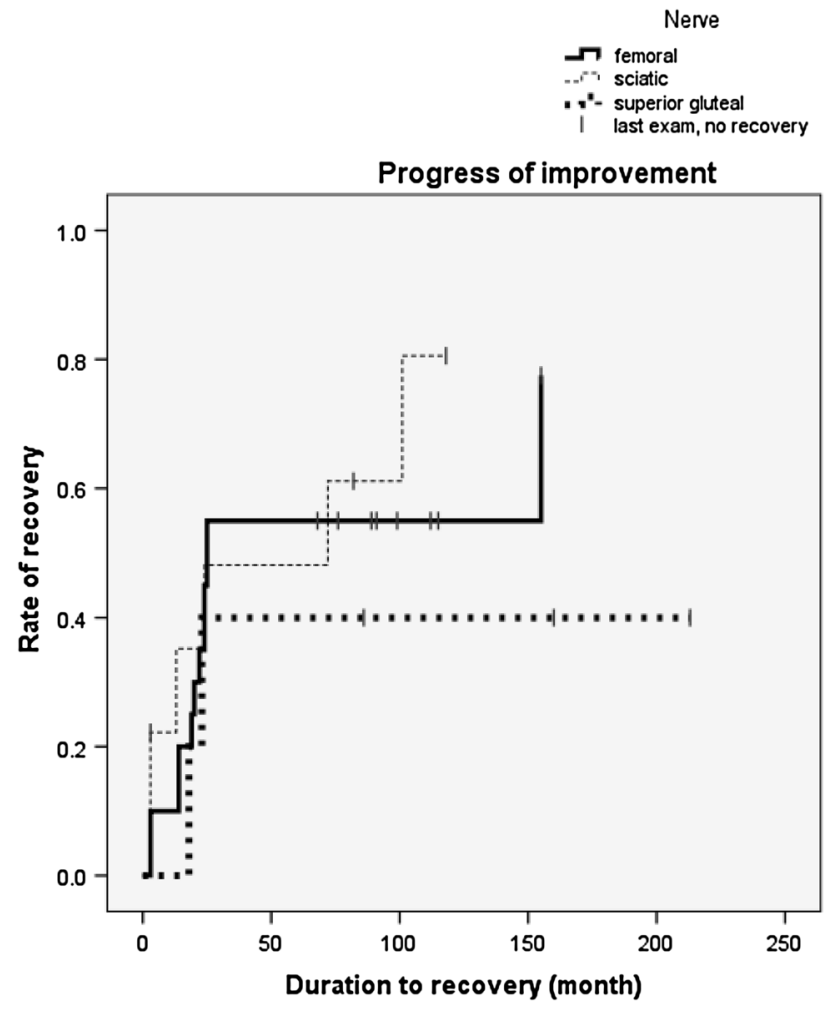

Fig. 1 Chronological development of improvement

Prognosis of the severe lesions according to the damaged nerve

Femoral, sciatic and superior gluteal nerve lesions were observed in the frequency relation of $4: 2: 1$. The femoral nerve lesions seem to carry a higher potential for recovery than sciatic or superior gluteal nerve lesions. $59 \%(9 / 17)$ with severe lesions of the femoral nerve had a full recovery (Table 3). But only $25 \%$ (1/4) of our severe sciatic nerve lesions and none of the two of the superior gluteal nerve fully restored. Brown et al. [2] describe a higher potential for recovery of sciatic nerves if the tibial division is affected instead of the peroneal one. This fits to our only patient without improvement with a nearly exclusive damage of the peroneal fibers of the sciatic nerve (No. 29 Table 4). On the other hand we have had another patient (patient No. 27) with severe sciatic nerve lesions with a similar EMG-result as patient No. 29, which showed no recovery but an improvement from M0 to M3 during the first 2 years postoperatively. So, affection of the peroneal fibers is maybe disadvantageous but even then, recovery is possible.

Overall, the incidence of postoperative nerve lesion is $1.5 \%$. This is in line with the literature. But in the majority of cases (20 of 34) the femoral nerve was affected. This is an incidence of $0.9 \%$. On one hand this is not higher than reported by Brown et al. [2], who reported an incidence of femoral nerve lesion after THA of 0.01-2.3\%. On the other hand this finding is contrary to most studies including Farrell et al. [5], where femoral nerve lesions were the most uncommon one. But in this study different approaches to the hip were analyzed and the approach according to Bauer was not included. Therefore, one possible explanation for this finding could be the approach. Only one study documented complications after THA with the Bauer approach [16]. In this study only 60 patients were examined and not any nerve lesion was documented. According to the very low incidence of nerve lesions after THA, this is not surprising. So, we cannot compare our finding of mainly femoral nerve lesions to the literature.

Further improvement later than 2 years after the incidence

Holzapfel et al. [8] claimed that later than 18 months since lesion you cannot expect a further regeneration. To our surprise we are able to show the contrary. At a late control 7 patients without full remission after 2 years could be reexamined. Six of them showed further improvement, three of them even reached full recovery. Because of death, loss to follow-up and poor general condition, 10 patients were missed for this late control. The authors are aware of this high number of missing data. But this does not change the finding that there is a high probability of further improvement up to full recovery after 2 years. We have to emphasize that in all our patients except one at least a slight improvement of the nerve function was documented.

\section{Male-female relation}

Our data confirm a higher risk of women (79\%) suffering a nerve lesion after THA as mentioned in the literature [10, $12,14,15]$. We have no explanation for this finding. Vascular changes after pregnancy [18], the higher rate of hip dysplasia and smaller bulk of muscle [19] are discussed as a possible reason.

Revision total hip surgery in our hands did not negatively influence the risk of nerve palsy.

\section{Conclusion}

Our classification in light (M3-4) and severe (M0-2) nerve lesions is of clinical significance. Light lesions reach full restoration in $91 \%$, most of them within 2 years. Severe lesions show full recovery only in $43 \%$ with a potential for further improvement after 2 years. We cannot demonstrate a significant difference in recovery potential between the affected nerves. Females show a significant higher risk to suffer a nerve lesion after THA. 
Acknowledgments We want to thank Susanna Häfliger for the data research and support.

Conflict of interest Authors have no conflicts of interest or financial ties to disclose.

Ethical standard This study was approved by the local ethical committee (Ref. 192/13).

\section{References}

1. Bauer R, Kerschbaumer F, Poisel S, Oberthaler W (1979) The transgluteal approach to the hip joint. Arch Orthop Trauma Surg Archiv fur orthopadische und Unfall-Chirurgie 95(1-2):47-49

2. Brown GD, Swanson EA, Nercessian OA (2008) Neurologic injuries after total hip arthroplasty. Am J Orthop 37(4):191-197

3. Daniels LWC (1986) Muscle testing: techniques of manual examination, 5th edn. Saunders, Philadelphia

4. DeHart MM, Riley LH Jr (1999) Nerve injuries in total hip arthroplasty. J Am Acad Orthop Surg 7(2):101-111

5. Farrell CM, Springer BD, Haidukewych GJ, Morrey BF (2005) Motor nerve palsy following primary total hip arthroplasty. J Bone Joint Surg Am 87(12):2619-2625

6. Fox AJ, Bedi A, Wanivenhaus F, Sculco TP, Fox JS (2012) Femoral neuropathy following total hip arthroplasty: review and management guidelines. Acta Orthop Belg 78(2):145-151

7. Goetz MB, Seybold D, Gosse F, Muhr G, Roetman B (2010) The risk of nerve lesions in hip alloarthroplasty. Zeitschrift fur Orthopadie und Unfallchirurgie 148(2):163-167

8. Holzapfel BM, Heinen F, Holzapfel DE, Reiners K, Noth U, Rudert M (2012) Nerve lesions after minimally invasive total hip arthroplasty. Der Orthopade 41(5):354-364

9. Kirschner S, Goronzy J, Storch A, Gunther KP, Hartmann A (2011) Avoidance, diagnostics and therapy of nerve lesions after total hip arthroplasty. Der Orthopade 40(6):491-499
10. Navarro RA, Schmalzried TP, Amstutz HC, Dorey FJ (1995) Surgical approach and nerve palsy in total hip arthroplasty. J Arthroplasty $10(1): 1-5$

11. Ochsner P, Brunazzi M (2003) Die Hüfttotalprothese: Implantationstechnik und lokale Komplikationen; eine Darstellung auf der Basis des Systems nach M. E. Müller unter Einbezug einer Langzeitkontrolle; mit 24 Tabellen. Springer, Berlin [u.a.]

12. Oldenburg M, Muller RT (1997) The frequency, prognosis and significance of nerve injuries in total hip arthroplasty. Int Orthop 21(1):1-3

13. Paterson D (1993) The International Documentation and Evaluation System (IDES). Orthopedics 16(1):11-14

14. Pekkarinen J, Alho A, Puusa A, Paavilainen T (1999) Recovery of sciatic nerve injuries in association with total hip arthroplasty in 27 patients. J Arthroplasty 14(3):305-311

15. Schoellner C, Schoellner D (2003) Nerve injuries in total hip arthroplasty - prophylactic strategies - quality assurance and risk management in orthopaedic and trauma surgery. Z Orthop Ihre Grenzgeb 141(3):289-295

16. Sendtner E, Borowiak K, Schuster T, Woerner M, Grifka J, Renkawitz T (2011) Tackling the learning curve: comparison between the anterior, minimally invasive (Micro-hip(R)) and the lateral, transgluteal (Bauer) approach for primary total hip replacement. Arch Orthop Trauma Surg. Archiv fur orthopadische und UnfallChirurgie 131(5):597-602

17. Simmons C Jr, Izant TH, Rothman RH, Booth RE Jr, Balderston RA (1991) Femoral neuropathy following total hip arthroplasty. Anatomic study, case reports, and literature review. J Arthroplasty 6(Suppl):S57-S66

18. Solheim LF, Hagen R (1980) Femoral and sciatic neuropathies after total hip arthroplasty. Acta Orthop Scand 51(3):531-534

19. Weber ER, Daube JR, Coventry MB (1976) Peripheral neuropathies associated with total hip arthroplasty. J Bone Joint Surg Am 58(1):66-69 